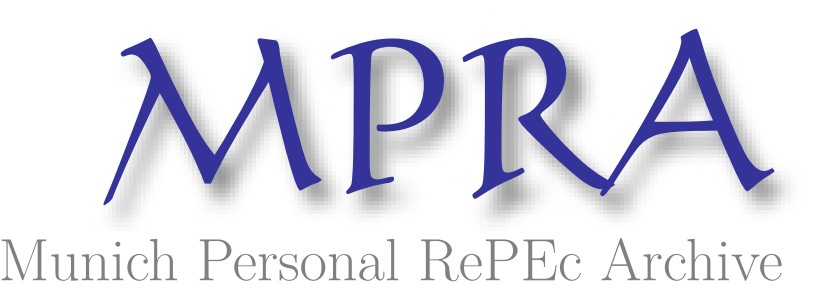

\title{
Cultural economy and the creative field of the city
}

Scott, Allen J.

2010

Online at https://mpra.ub.uni-muenchen.de/32108/

MPRA Paper No. 32108, posted 14 Jul 2011 12:41 UTC 


\title{
CULTURAL ECONOMY AND THE CREATIVE FIELD OF THE CITY
}

\author{
by
}

Allen J. Scott

SCOTT, A. J. (2010): 'Cultural economy and the creative field of the city', Geografiska Annaler: Series B, Human Geography 92 (2): $115-130$.

\begin{abstract}
I begin with a rough sketch of the incidence of the cultural economy in US cities today. I then offer a brief review of some theoretical approaches to the question of creativity, with special reference to issues of social and geographic context. The city is a powerful fountainhead of creativity, and an attempt is made to show how this can be understood in terms of a series of localized field effects. The creative field of the city is broken down (relative to the cultural economy) into four major components, namely, (a) intra-urban webs of specialized and complementary producers, (b) the local labour market and the social networks that bind workers together in urban space, (c) the wider urban environment, including various sites of memory, leisure, and social reproduction, and (d) institutions of governance and collective action. I also briefly describe some of the path-dependent dynamics of the creative field. The article ends with a reference to some issues of geographic scale. Here, I argue that the urban is but one (albeit important) spatial articulation of an overall creative field whose extent is ultimately nothing less than global.
\end{abstract}

Key words: creative field, creativity, cultural economy, innovation, urban planning, urbanization.

\section{Introduction}

It is widely recognized that the character of production and work in the contemporary economy has undergone a major sea change by comparison with the state of affairs that prevailed over much of the previous century (cf. Amin 1994). The new structures of production and work that are now so strongly (though by no means exclusively) evident in both advanced and less advanced economies have been variously categorized by labels such as flexible specialization, post-fordism, the knowledge economy, or sometimes, simply, the new economy. One recent formulation refers to "cognitive capitalism' (Moulier-Boutang 2007) and another to the 'cognitive-cultural economy' (Scott 2007). Whatever rubric we may choose to designate the overall character of production and work in today's econ- omy, one of the prominent features of these phenomena is that they are associated with high levels of computerization and incessant innovation in both process and product configurations, especially when compared with the economy of mechanization and repetition that dominated up to about the 1980s (cf. Corsani 2003; Levy and Murnane 2004; Autor et al. 2006). By the same token, the emergence of the new economy has been accompanied by a significant expansion in the number of workers endowed with high levels of human capital in regard to functions such as analytical thinking, judgement and decision-making, fluency of ideas, social perceptiveness, capacities for interaction with others, and imaginativeness, as well as in regard to substantive knowledge and expertise (in technology, medicine, business, policy analysis, the arts, and so on). Nowhere have these changes been more evident than in the great metropolitan areas of the modern world, though many cities at the lower end of the urban hierarchy have also participated to greater or lesser degree in the same trends, as in the case of the small craft and cultural centres that abound in modern Italy (for examples, see, Cuccia and Santagata 2002; Aage and Belussi 2008; Mizzau and Montanari 2008). Small wonder, in the light of these observations, that topics such as creativity, innovation, human capital, the creative class, and creative cities, should have risen to the top of the research agendas of many geographers, regional scientists, and sociologists of late years.

The present article is an attempt to explore further this terrain of investigation via an inquiry into the conditions that engender "creativity" in contemporary cities, and its expression in urban development generally. I put the term creativity in quotation marks, because its meaning is by no means selfevident. Actually, and in view of its current vogue, the term calls urgently for substantive clarification. I 
proceed with these tasks on the basis of a more or less exclusive focus on the cultural side of the cognitivecultural economy, and where by the cultural side I mean all those sectors of the modern economy (in contrast, say, to high-technology industry or business and financial services) specializing in the production of goods and services whose consumer appeal is derived pre-eminently from the fact that they transmit non-utilitarian aesthetic and semiotic signals. I am confident that much of the following analysis will be found pertinent to other segments of contemporary cognitive-cultural capitalism, but the cultural economy, as such, offers a special challenge given the intensely symbolic nature of its final outputs and the strong creative urges out of which they frequently arise. In particular, culture is often seen as a sort of privileged sphere of creativity, one that is free from the physical conditions that constrain innovation in, say, the domain of science and technology, and where, in some accounts, the human imagination is ultimately at liberty to soar upward in the quest for hitherto undreamt of forms of selfexpression. For this reason alone, a critical focus on the cultural economy in the contemporary city poses the problem of creativity (in both analytical and policy terms) in a notably stark and unadulterated manner. This focus is all the more interesting in view of the rapidly rising significance of the cultural economy as a driver of growth in many different cities in the modern world. These issues all come to a head with special force around the currently fashionable question of creative cities, and a large part of my objective, in the end, is to provide a theoretically viable view of the question that simultaneously underscores the vacuity of at least some of the nostrums currently being retailed under this rubric to policy makers as practical formulae for fostering urban development and growth.

\section{The cultural economy in US metropolitan areas}

There has been much, albeit inconclusive, discussion in recent years about the precise definition of the cultural (or creative) economy and its sectoral and occupational composition (Pratt 1997; Power 2002; Markusen et al. 2008). This inconclusiveness is scarcely surprising in view of the circumstance that no hard and fast line can be drawn between purely symbolic goods and services on the one hand and purely utilitarian ones on the other hand. Rather, there is an unbroken continuum of types ranging from one extreme to the other, and whose middle ranges contain a huge diversity of hybrid artefacts, such as newspapers, furniture, travel accessories, culinary products, or cars. Suffice it to say, for present purposes, that the analysis to be undertaken here is focused on the more symbolic extreme of this continuum, as represented by industries like film, television-program production, music, electronic games, tourism, architecture, advertising, fashion clothing, jewellery, and so on. These kinds of industries typically represent anything from 4 to 8 per cent of total employment in today's more advanced economies, and their relative importance is growing rapidly. In the case of major metropolitan areas like New York, Los Angeles, London, Paris, Milan, Tokyo, and so on, the incidence of employment in the cultural economy may rise to levels as high as 25 to 40 per cent of the total (Scott 2000).

A broader sense of the empirical extent and geography of the cultural economy in the United States today may be conveyed with the aid of some simple census data. As already suggested, there can be no finality about any definition of the cultural economy, but I have chosen to seize it here in terms of a core group of eleven occupations that are focused unambiguously on aesthetic and semiotic pursuits. These occupations are listed in Table 1 together with employment statistics for 2000 and 2008. Total employment in these occupations in the United States was a little over 2.6 million in the year 2008 , an increase of 7.31 per cent over the corresponding figure for 2000. The selected occupations account for just 0.87 per cent of all US employment, but they can nonetheless be taken as highly representative markers of the cultural economy generally. Of course, they are only the tip of the iceberg formed by a considerably larger employment system in related occupations and sectors. Location quotients of employment in this aggregate group of occupational categories were computed for all 283 metropolitan areas as identified in the 2000 Census of the United States. The simple correlation of these location quotients with the logarithm of total metropolitan population for all 283 metropolitan areas is 0.40 , suggesting that the incidence of the cultural economy becomes more and more pronounced as we move up the urban hierarchy. A total of 66 of all the metropolitan areas in the United States in the year 2000 had location quotients equal to 1.75 or more, indicating that they are places where significant concentrations of the cultural economy occur. These metropolitan areas are all shown in Figure 1.

The most obvious feature by far in Figure 1 is 
Table 1. Core cultural occupations in the United States and levels of employment, 2000 and 2008.

\begin{tabular}{|c|c|c|c|c|}
\hline \multirow{2}{*}{$\begin{array}{l}\text { Census } \\
\text { code }\end{array}$} & \multirow[b]{2}{*}{ Designation } & \multicolumn{3}{|c|}{ Employment } \\
\hline & & 2000 & 2008 & Percent change \\
\hline 130 & Architects, Except Naval & 216,867 & 225,357 & 3.91 \\
\hline 260 & Artists and Related Workers & 292,315 & 256,660 & -12.20 \\
\hline 263 & Designers & 894,897 & 967,567 & 8.12 \\
\hline 270 & Actors & 55,906 & 60,781 & 8.72 \\
\hline 271 & Producers and Directors & 157,141 & 160,797 & 2.33 \\
\hline 274 & Dancers and Choreographers & 34,340 & 30,076 & -12.42 \\
\hline 275 & Musicians, Singers, and Related Workers & 206,872 & 231,554 & 11.93 \\
\hline 283 & Editors & 204,926 & 202,897 & -0.99 \\
\hline 285 & Writers and Authors & 197,177 & 233,119 & 18.23 \\
\hline 291 & Photographers & 151,607 & 202,159 & 33.34 \\
\hline \multirow[t]{3}{*}{292} & Television, Video, and Motion Picture & & & \\
\hline & Camera Operators and Editors & 36,487 & 56,667 & 55.31 \\
\hline & Totals: & $2,448,535$ & $2,627,634$ & 7.31 \\
\hline
\end{tabular}

Sources: US Census 2000, and American Community Survey 2008.

the prominence, both absolutely and relatively, of New York and Los Angeles as centres of the cultural economy, with San Francisco in distant third place no matter whether measured in terms of location quotients or total employment in the designated occupations. There is, at the same time, a quite diverse set of smaller metropolitan areas with flourishing cultural economies. Notable examples here are tourism and vacation centres like Miami, FL, and San Diego, CA; convention and resort hubs like Orlando, FL, and Las Vegas, NV; music agglomerations like Austin, TX, and Nashville, TN; craft and heritage places like Santa Fe, NM, and Savannah, GA; university towns like Madison, WI, and State College, PA; and cities with unusually affluent populations like Santa Barbara, CA, and Stamford, CT, that maintain high levels of cultural services and are attractive to artists, designers, and writers as places in which to work and live. Not all of the metropolitan areas shown in Figure 1 have full-blown cultural economy clusters in the Marshallian sense but all are symptomatic of the recent rapid rise of the cultural economy in its many different guises in the United States today, and of its special affinity for large and dense urban areas. Well-developed Marshallian clusters are especially characteristic of cultural production sectors in New York and Los Angeles. The central areas of both of these cities are encircled and interpenetrated by specialized industrial districts in sectors such as motion pictures, music, multimedia, architecture, fashion, jewellery, furniture, interior design, live theatre, and many others, not to mention bohemias and near-bohemias like Chelsea and Greenwich Village in New York or Echo Park and Silverlake in Los Angeles with their ecosystems of artists' studios, clubs, galleries, coffee houses, and so on (Lloyd 2002; Indergaard 2004; Rantisi 2004; Scott 2004; Currid 2007; Halle and Tiso 2008).

Marshallian clusters can be characterized in terms of two very general features that account in significant degree for their peculiar spatial form. In the first instance, they are constituted in organizational terms as networks of complementary but specialized firms working in competition and collaboration with one another. The high levels of uncertainty that firms producing cultural products typically face in final markets accentuates the network or transactions-intensive character of production, for uncertainty tends to induce high levels of vertical disintegration as a way of reducing intrafirm misallocation of resources (Scott 2006). The talent-based nature of production encourages yet further disintegration because so many producers in the cultural economy are constantly in search of new combinations of creative labour in attempts to capture market share through the effects of novelty and product differentiation (Gil and Spiller 2007). For this reason, too, producers are apt to adjust their upstream and downstream network relations radically from one production period to the next as a function of their shifting output specifications. This volatility alone, as we shall see, drives a certain kind of creativity in the cultural economy. In the second instance, these clusters also function as the polar axes of dense local labour markets that 


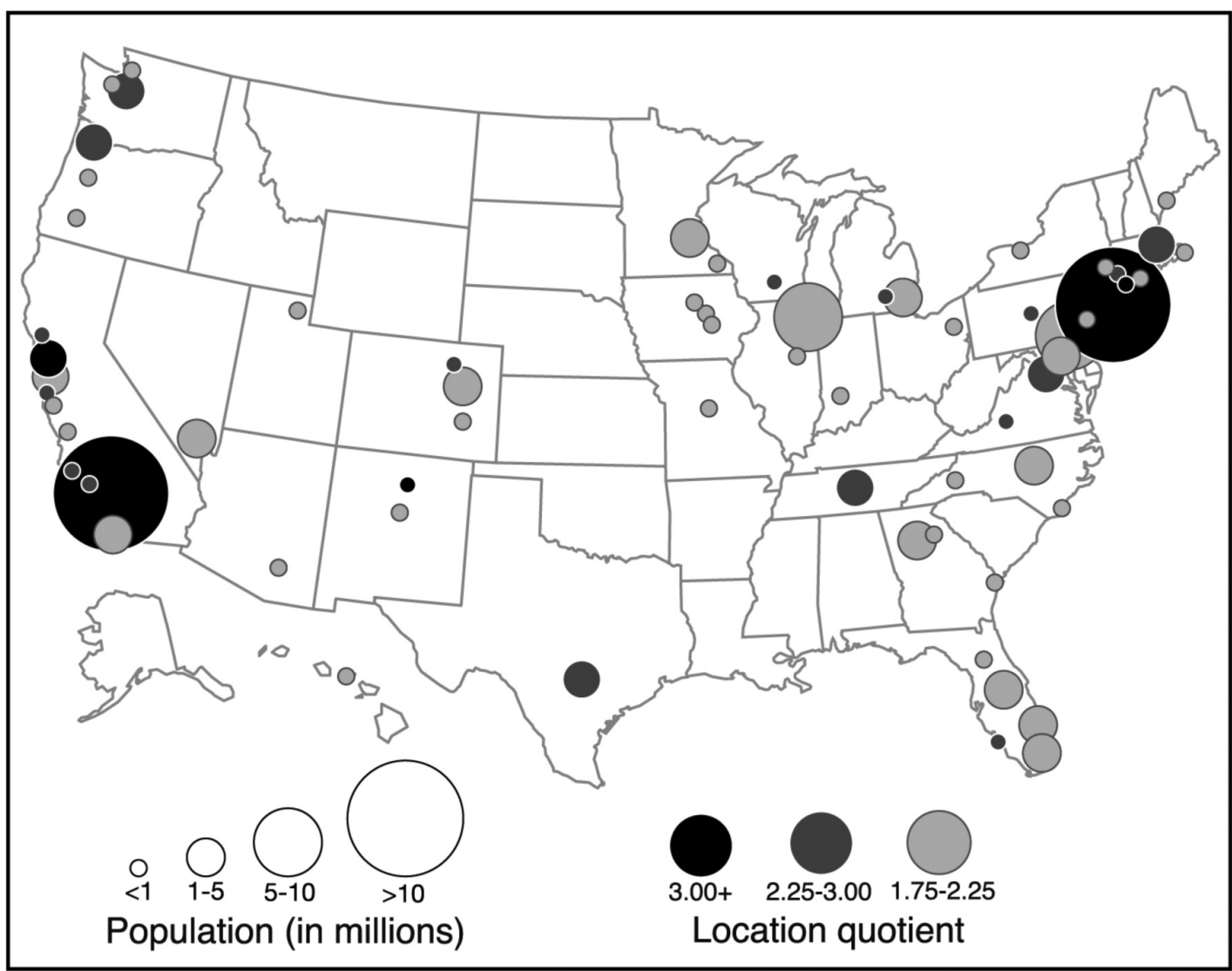

Fig. 1. Cities with a high incidence of aggregate employment in core cultural occupations in the United States. All cities shown have location quotient values of 1.75 or more.

ramify through local residential areas (and in such a way that the magnetic attraction exerted by any given employment cluster on surrounding neighbourhoods diminishes with commuting distance). Labour markets of this sort are highly multifaceted, in that the local workforce usually embodies many different skills, aptitudes and sensibilities, reflecting the wide range of human capital demands in the cultural employment system. Different fractions of the workforce tend to be at least partially segregated from one another in the residential space of the city, and this observation in turn encourages the speculation that such segregation may have at least some relationship to processes of social reproduction and may therefore be directly or indirectly susceptible to valorization in the workplace. ${ }^{1}$

It is precisely the status of complexes of cultural producers as webs of interrelated firms and dense foci of employment that accounts in large degree for their emergence as distinctive nodes in the urban landscape. Clustering, in brief, helps to streamline inter-firm transacting activities and to enhance local labour market operations such as commuting, job search, and the matching of employees and jobs. At the same time, clustering augments the creative capacities of firms and workers by bringing many diverse units of decision-making and behaviour into close contact and communication with one another; and this feature in turn further magnifies the incentives for producers to converge locationally together. The latter proposition can be generalized by noting that clustering not only reduces the costs of both traded and untraded interdependencies (both between firms and within the local labour market) but is also a source of self-reinforcing increasing returns effects or agglomeration economies. Not least among these agglomeration economies are spontaneous information spillovers that stimulate creativ- 
ity and that partially drive the chronic syndrome of ever-shifting product designs and symbologies that runs rife through much of the modern cultural economy.

\section{Interlude: creativity in social context}

Creativity is an extraordinarily difficult word that means many different things to different people. I cannot deal with all of these ambiguities in this brief interlude, though I do seek to establish a few ground rules as to the significance and use of the word for the purposes of the present analysis. As part of this task, and right at the outset, we need to distinguish between three closely related terms, namely, learning, creativity and innovation. As a rough first approximation, I shall take it here that learning provides important informational and procedural foundations for creative activity; ${ }^{2}$ creativity itself is more concerned with thought and action (at the level of both the individual and the group) directed to the production of novel insights and perceptions that may or may not eventually have tangible significance; innovation derives from these insights and perceptions but is more specifically focused on their implementation in various domains of practical application. To be sure, the lines of separation between these terms can never be drawn with any degree of sharpness. For this reason, I shall occasionally conflate the three in what follows, though the emphasis is always upon creativity as the active agent of ameliorative change. This point is all the more to be underlined because learning does not always lead to creativity, and innovation as defined may sometimes involve nothing more than secondhand appropriation or imitation of the creative ideas of others.

It must be further stressed that the notion of creativity is inevitably caught between two polarities, one psychological, the other sociological. On the one side, creativity resides in the personal endowments and capacities of individual subjects. Some individuals have the native talent and/or acquired know-how for certain kinds of creative acts; some have little or none. Much useful analysis has been published on this aspect of the problem (for a summary, see Sternberg and Lubart 1999). On the other side, creativity is also embedded in concrete social contexts that shape its motions and objectives in many different ways (cf. Csikszentmihalyi 1990; Seitz 2003; Hemlin et al. 2008; Heßler and Zimmermann 2008; McIntyre 2008). It is this sec- ond facet of the problem that is most pertinent to any conceptualization of the creative field, though we should certainly not allow ourselves to fall into an untenable dualism that separates these two moments of creativity into watertight compartments. In other words, a large part of my objective in the present article is to consider the reflexive interactions between individual expressions of creativity and the social milieu, but with dominant reference to the latter. In somewhat equivalent terms, we are concerned here with the ways in which the habitus, as identified by Bourdieu (1980), is adapted to social context (and, eventually, to the context of urbanization) and how creative acts within the habitus are in turn materialized in social practices. Four broad points now need to be made.

First, creative thinking is always in important respects moulded by the knowledge and skills of individuals. These assets are acquired to a large extent through education, practice and informal socialization, that is, from external sources that are themselves permeated with definite historical and geographical character. Similarly, skills and knowledge are bound by all manner of checks and limits (e.g. by theoretical closure, by normative ideologies, by historical tradition) though the degree of rigidity of these constraints will vary greatly depending on specific circumstances. Thus, communities of harpsichord makers are doubtless likely to be rather conservative in their practices, whereas communities of digital-effects workers are presumably more prone to strive for radical innovations in their particular domain of activity (cf. Brown and Duguid 1991; Amin and Roberts 2008). The point, however, is that the individuals who compose each community typically internalize elements of their daily environment and reflect these back in more or less socially conditioned creative efforts.

Second, to be socially meaningful, the products of creative work must eventually be recognizable as such by others. Some theorists go so far as to claim that creativity does not exist except as a quality that - for whatever reason - has inter-subjective significance and that can therefore be apprehended by third parties. In a somewhat analogous but very much more provocative comment, Bastide (1977, p. 44) writes that 'we do not admire the Venus de Milo because it is beautiful; it is beautiful [i.e. an expression of creativity] because we admire it' (see also Csikszentmihalyi 1990). ${ }^{3}$ In any event, meaningful forms of creativity must always be able to connect with an audience or a market. This meaningfulness 
criterion is particularly potent in the present instance, for even though the outputs of the cultural economy have high symbolic meaning, this system of production is also regulated by the down-to-earth goal-oriented strategies of firms and workers structured as they are by a significant concern for monetary returns to investment and effort in the context of market forces. Those who pursue goals outside of this framework may possibly attain to high levels of personal satisfaction, but except in rare cases, their labours are not much likely to generate significant material rewards.

Third, and as a corollary, the wider structures of external transacting within which firms and workers inevitably operate have important consequences for the unleashing of creative labour. Individuals caught up in dense transactional networks are obviously in a more favoured position to acquire useful information and to explore its wider meanings by discussion with their interlocutors than those who are more socially isolated. Some of this information, too, will often throw new light on old ways of proceeding, thus presenting challenges to established patterns of thought. This destabilizing effect is no doubt more prone to occur in relatively unpredictable situations, as in the case of firms subject to a rapidly changing technological environment or facing a continually shifting terrain of competition. Nooteboom (1999) suggests, in addition, that interpersonal cognitive distance (further refined in terms of novelty and communicability) is an important intermediate variable in the way this kind of stimulus works. Too little novelty or communicability in any given transaction is unhelpful because it merely reinforces what is already known; and so is too much, because it may not be decodable at the point of reception; intermediate doses of both are calculated to push learning and creativity forward most rapidly (Nonaka 1994; Uzzi and Spiro 2005). Some degree of mutual trust is also presumably important in facilitating communication, especially where exchanges of tacit knowledge are at issue. In fact, much work in the new economy is organized specifically in ways that seek to capture and optimize these transactional aspects of creativity. As Grabher (2001) has written, this manner of organizing the labour process is especially evident in the case of project-oriented teams where selected individuals are brought together for a period of time in order to pool their know-how and to cross-fertilize each other's thinking in a context of close collaboration directed to problem-solving exercises (see below).
Fourth, the terrain of creativity, comprising as it does strong contextual and relational components with varying degrees of inertia suggests that creative activities are prone to be marked by pathdependency. Where such path-dependency prevails, the creative powers of the labour force will be all the more likely to move in channels that are closely regulated by wider social conditions. An important manifestation of this phenomenon is apparent in the emergence of what Dosi (1982) calls 'technological paradigms' qua integrated structures of knowledge and practice in industrial systems. Prevailing paradigms facilitate certain kinds of (intra-paradigmatic) innovation yet simultaneously put obstructions in the way of extra-paradigmatic exploration. In the same manner, we might refer to aesthetic and semiotic genres or archetypes as establishing relatively durable frames of reference for creativity in the cultural economy. Accordingly, and in parallel with the piling up of knowledge in technological paradigms, accumulations of substantive and stylistic experiments proceed within design archetypes, thus providing a growing pool of assets to be exploited by workers in any given socio-cultural context. For various reasons - radical social change, for example, or new breakthroughs in science, or exhaustion of a given aesthetic genre - established paradigms and archetypes may start to wither and new creative pathways be set on foot. Something analogous to this, or more accurately perhaps, sub-archetypal transformation, appears to happen with a fair degree of frequency in the popular music industry as marked by what Peterson and Berger (1975) identify as 'cycles in symbol production', in other words shifting musical genres combined with alternations in the dominance of mainstream and peripheral performers in final markets. In addition, underlying shifts in prevailing technological paradigms may well have dramatic effects on aesthetic and semiotic archetypes - and hence on creative expression - as illustrated by the impact of sound recording on the Hollywood motion-picture industry in the 1930s, or the transformative influence of digital visual effects on the making of films today (Scott 2005). By contrast, long-term lock-in to given archetypes may be expected in social situations where high levels of stability and conservatism prevail. The point can be illustrated by reference to communities of religious painters in India, where entrenched traditions and norms impose strict limits on artistic experimentation beyond historically established protocols (Maduro 1975; Bautès and Valette 2004). 
These four main points help us to begin the task of grounding the notion of creativity in the concrete realities of existence and as a social phenomenon in its own right, bounded in various ways in space and time (Törnqvist 2004). Concomitantly, they serve to cast serious doubt on any conception of creativity as some sort of inchoate manna that descends on gifted individuals, whether poets, or scientists, or members of the "creative class", and that is then transcribed by these individuals into ground-breaking insights for diffusion to the sublunary world. The same four points now provide some basic tools for formulating a theoretical description of the creative field of the city and for comprehending why it is that cities so often function as unusually potent vortexes of creativity, though always in circumstances that are historically and geographically definite. It is worth adding that these remarks about the nature of creativity find many resonances in modern theories of artistic and scientific production generally. The social conditions of creativity in these spheres have been examined by commentators such as White and White (1965), Hennion (1981), Becker (1982) and Crane (1992), among many others. Authors like these argue that aesthetic and epistemic communities, and the modes of inspiration and inventiveness that they display, all bear mediated relationships to wider social forces and to the specific forms of expression that they foster. This is the message of social epistemology more generally, with its emphasis on the essential immanence of all varieties of knowledge (Mulkay 1972; Latour and Woolgar 1979; Barnes et al. 1996).

\section{The creative field of the city}

\section{Preliminary considerations}

I have argued that creativity can be seen explicitly as a social phenomenon entwined within overlapping sets of social relationships that significantly influence its substance and form. It follows immediately that geography is implicated in these matters, for all social relationships are necessarily characterized by extension in space. Indeed, on further examination, the geographic dimension turns out to be extraordinarily potent as a medium of variation in creative energies.

This geographic dimension can initially be represented simply as a Cartesian grid of points and lines, or more concretely, as a locationally distributed collection of phenomena like firms, workers, schools and universities, research laboratories, com- munications links, institutions and associations, and other disparate phenomena, interrelated with one another at many different gradations of intensity. In a more analytical vein we need to note that this grid exhibits a multiplicity of spatial and organizational levels, and that each level is further arranged in very specific ways with strong implications for creative outcomes. The intra-urban scale represents one level at which the grid is especially well developed, above all in view of the dense, multifaceted, and highly interdependent character of the relata of modern cities. Important elements of the grid at this scale thus constitute the urban creative field, that is, they represent a spatially organized and tensionfilled system of interacting phenomena with significant effects on learning, creativity, and innovation. I shall argue that the creative energies of this field are fundamentally powered by the production system of the city, though always in the context of a wider urban environment (Storper and Scott 2009). For instance, in the nineteenth century, Manchester and its satellite towns in Lancashire were hotbeds of discovery in regard to textile manufacturing. In Detroit in the middle of the twentieth century, innovation was focused on the automotive industry and its adjunct sectors. As the century wore on, Silicon Valley emerged as a focus of new process and product developments in the semiconductor, computer, and software industries. At the dawn of the twentyfirst century, the cultural economy of numerous city-regions across the world has developed into a nexus of creativity as expressed in many different sectors devoted to the packaging and commercialization of story-telling and visual experiences, design and fashion initiatives, the presentation of information, vicarious encounters, forms of distraction and edification, and so on.

The creative field of the city can be seen, in short, as a system of cues and resources providing materials for imaginative appropriation by individuals and groups as they pursue the business of work and life in urban space. But it is also a sort of canvas on which creative and innovative acts are variously inscribed. Within this field, individuals are continually if intermittently entangled in transactional exchanges with one another, and in this manner they receive and emit signals that are variously charged with information. The same individuals consciously and unconsciously absorb elements of locally accumulated epistemic and cultural traditions; they become habituated to routines in urban production space as in urban social space; they encounter and 
deal with numerous challenges thrown out by the evolving local economy; and with the deployment of their creative energies, as expressed above all in specific forms of competitive advantage, an urban and regional dynamic of path-dependent development is set in motion. ${ }^{4}$ These general ideas, of course, are far from new, and elements of them can be found in the literature on such topics as the innovative milieu (Aydalot 1986; Maillat and Vasserot 1986; Camagni 1995), the learning region (Florida 1995; Storper 1996; Morgan 1997), regional innovation systems (Cooke and Morgan 1998; Oinas and Malecki 1999), and the like. My present objective is to try to sharpen some of the theoretical bases of this literature by carrying its main thrust forward from a dominant concern with technologyintensive industry to a focus on symbol-intensive production in the cultural economy. One important consequence of this shift of emphasis, as we shall see in due course, is the need to pay very special attention to the cultural resonances of place.

\section{Transactional networks in the cultural economy of the city}

We have already engaged in a first round of discussion on the transactions-intensive nature of the cultural economy and its concomitant tendency to condense out within the urban landscape in specialized clusters of productive activity. As we also learned, producers in these clusters are much given to relatively ephemeral commercial relations with one another, no matter whether they take the form of ordinary input-output or manufacturer-subcontractor interactions (as in the fashion industry) or temporary coalitions of firms in pursuit of a given creative project (as exemplified by much productive activity in the motion-picture or music industries). In the latter instance, selected firms come together in networks of collaborative effort only to break apart again as their work bears fruit and then to re-emerge in different configurations as other projects appear on the horizon.

All of this transacting activity involves much interpersonal contact and communication, and most notably intense face-to-face interaction among workers in different firms. This kind of interaction occurs especially, but not entirely, among individuals in the upper echelons of the managerial and creative hierarchy. Accordingly, large quantities of information tend to circulate with some rapidity through the extended network structures of the urban production system. Much of this information will no doubt be of limited value. However, at least some of it will occasionally prove to be directly useful to recipients. Some of it, too, will combine with other information in recipients' minds thereby setting the scene for unexpected insights and possible new ways of approaching the challenges of production and work. In addition, the dialogue that almost always accompanies face-to-face encounters is itself a means of generating increments to awareness and know-how, for as the interlocutors involved in the dialogue encounter problems of mutual comprehension or of knowing how to proceed further in their discussions they will often invest further time in seeking jointly to resolve these problems. Much empirical research on industrial innovation has demonstrated the importance and pervasiveness of these processes (e.g. Russo 1985; von Hippel 1988). Other work, such as that pioneered by Jaffe et al. (1993) on interrelated patent citations also points in the same direction by showing that many types of industrial clusters are rife with localized innovation-inducing spillovers. Moreover, in addition to the explicit forms of information that are passed on in these sorts of transactions, there are also tacit messages that are often only transmitted at a semiconscious level. This feature is of great importance in the cultural economy where transactional exchanges not only convey information in the usual sense but also help to diffuse attitudes, ways of seeing, forms of emotional responsiveness, stylistic gestures, and so on.

These transactions-based outcomes are amplified in situations where firms face high levels of instability and insecurity. Producers in the cultural economy are unusually susceptible to these hazards, and thus they have strong incentives to adjust their process and product configurations more or less continually, leading in turn to frequent shifts in their external transactional relations. Producers in the cultural economy are also presumably much given to overall scanning of surrounding firms in the unending search for prospective transactional partners. In these broad conditions of uncertainty, and so long as external markets are expanding over time, the density of intra-cluster transactions will tend to grow because vertical and horizontal disintegration, that is spinoff, will also tend to proceed at a rapid pace, thus enhancing local creativity potentials. Firm spinoff processes are mediated in practice by entrepreneurs bent on realizing imagined new possibilities within the organizational structure 
of production, and are hence themselves reflections of deeply-rooted creative urges. Further, in a study of major fashion agglomerations around the world, Wenting (2008) argues that localized spinoff processes are critical mechanisms for transferring knowledge and know-how (though hedged in by inherited routines) from established to new firms and hence for preserving the innovative capacities of any given agglomeration.

\section{The local labour market and the employment rela- tion}

In addition to their role as centres of production, cities also function as multifaceted reservoirs of labour that engender countless emergent effects in regard to creativity. For one thing, workers in urban areas constantly rub shoulders with one another both in workplaces and in residential neighbourhoods. For another thing, as we shall see in this section and the next, cities are places offering special conditions that favour social reproduction of highly skilled and creative workers. Accordingly, just as interaction via inter-firm transactional structures enhances information spillovers and the transmission of aesthetic and semiotic values so, too, an ever changing backdrop of interpersonal contact in the city promotes varying degrees of common cultural understanding. The inter-firm networks that play such a prominent part in these processes of mixing and interconnection find a direct echo in project-oriented teams of workers. These teams may comprise employees of a single firm or multiple firms, and they not infrequently include freelance and temporary workers as well. Team work helps to stimulate individual creative activity and to promote joint creative synergies, and is therefore widely practiced where multidimensional but discrete projects are at stake. In the cultural economy these projects invariably change their substantive content and design specifications from one instance to the next so that teams rarely survive intact for very long. Instead, as any given team breaks up, the individual workers that were involved proceed with their accumulated experience and know-how to recombine with other workers in other teams thereby establishing the creative process anew. Concomitantly, cultural workers face many systemic difficulties due to the marked insecurities of the job market, as well as to the rapidly revolving system of fads, fashions, and tastes that always threatens to devalue their skills and reputations. In response to the insecurities of this situation cultural workers commonly devote considerable amounts of time outside the workplace to strategic socialization with each other in the effort to maintain an edge in local labour markets (Scott 1998). This behaviour entails both formal and informal mixing in networking organizations and associations in order to acquire useful information and gossip about possible job openings and overall industry trends, and to exchange opinions about production and work in general. Ursell (2000) has referred to this kind of activity as an 'economy of favours'. Thus, both in the workplace and out of the workplace, individual workers in the cultural economy are almost always caught up in webs of socially-coordinated career paths whose continual if often irregular intersection helps to sustain and to promote their creative capacities (Montgomery and Robinson 1993).

The creative dynamism of local labour markets in the cultural economy is further bolstered by basic infrastructures of schools, colleges, and universities with curricular and research programmes that reflect various aspects of the local economy. These institutions sustain a supply of specialized creative workers whose skills and talents are usually well attuned to local needs. In addition, and certainly in the case of the most dynamic centres of the modern cultural economy, the intra-agglomeration supply of qualified labour is complemented by a process of 'artistic gravitation' (Menger 1993), namely, inflows of talented migrants who recognize that their ambitions are most likely to be satisfied in specialized clusters where their aptitudes are most in demand. This phenomenon can be illustrated by the persistent convergence of would-be actors, directors, musicians, and so on, from all over the world into the entertainment complex of Hollywood, hence continually reinforcing the local pool of creative labour.

\section{Cultural economy and the phenomenon of place}

An added ingredient in this rich creative mix of inter-firm networks and local labour market relationships is place itself, not only as a spatial aggregation of industrial capabilities and skills, but also as a stockpile of knowledge, traditions, memories, and images. These assets function as sources of inspiration for artists, designers, craftsworkers, and other creative individuals. As such, they also leave traces on the final products of these workers, imbuing them with an air of authenticity, and hence also contributing to the logic of product differentiation characteristic of so much of the modern cultural 
economy (Drake 2003; Rantisi 2004; Santagata 2004; Asheim and Coenen 2005). A striking instance of this proposition is evident in the films that emanate from Hollywood and Paris, reflecting as they do distinctively different cultural traditions and values congealed in the character of each of these places as centres of cinematic production and as concentrations of urban life. Similarly, Grabher (2001) refers to the bland market-research led products of New York advertising firms as opposed to the humour, irony and self-deprecation that characterize the copy-writing activities of London firms. In a more general way, London theatre, Nashville music, Danish furniture, or pottery from Caltagirone are not just generic theatre, films, music, furniture, and pottery, but each in its own way a genuine expression of an accumulation of past accomplishments. These place-specific products accordingly possess distinctive qualitative features and are inscribed with localized reputation and authenticity effects, and thus they can be imitated but never completely replicated elsewhere (Molotch 1996). Authenticity in this sense is perhaps one of the few residual constituents of the auratic power that, as Benjamin (1969) writes, once inhabited aesthetic objects at large, but 'that withers in the age of mechanical [or electronic] reproduction'. The creative integrity of centres with these kinds of competitive advantages is in many cases protected by intellectual property law instruments such as regional warranties, AOC rights, trademarks, and brands. The association between place and product, moreover, tends to be self-reinforcing over time because both of them are joined together in a spiral of mutual interdependencies built upon the creative reprocessing of old images and the continual addition of new ones to local repertoires of designs and symbologies. The case of Los Angeles - or of Hollywood more specifically - is paradigmatic here.

At the same time, the phenomenon of place incorporates not just the local economy, but also the wider built environment and social milieu, both of which play supplementary but significant roles in the shoring up of place-specific creative energies. The most advanced cases of this state of affairs are to be found in the great city-regions of the modern world like New York, London and Paris. Parts of these cities display a more or less organic continuity between the local physical environment (as expressed in streetscapes and architecture), associated social and cultural amenities (museums, art galleries, theatres, shopping and entertainment facilities, and so on), and adjacent industrial/commercial districts specializing in activities such as advertising, graphic arts, audiovisual production, publishing, or fashion design, to mention only a few. These complex urban ecologies furnish many of the raw materials of the contemporary cultural economy. As Currid (2007, p. 185) writes, with reference specifically to New York, 'the city ... allows for the production of culture, not just in galleries and music venues but in bars and nightlife and on the street.' In numerous cities, these synergies are heightened by the reorganization of critical sections of their internal spaces like theme parks and movie sets, as exemplified by Times Square in New York, The Grove in Los Angeles, or the Potsdamer Platz in Berlin, and by the erection of dramatic architectural set-pieces in the guise of signature buildings by internationallyacclaimed architects (Zukin 1991; Roost 1998; Hutton 2008). The iconic quality of these set-pieces often helps to secure the branding of the cities in which they are located as distinctive centres of creativity and foci of global attention. Extensive gentrification of inner city neighbourhoods highlights these effects, both by reason of its transformational impacts on the visual aspect of inner city areas as well as by its function in extending the supply of residential space for young professional workers, providing them with ready access to major foci of creative work in the city and to many of the city's most alluring cultural amenities. To round out this description, we might say that a city with these kinds of attributes achieves something approaching the final seal of creative accomplishment when it becomes the acknowledged haunt of a mediatized cadre of individuals (such as le ToutParis or Swinging London) distinguished by their glamour and celebrity, and who function - for better or worse - as a reflection of and an advertisement for the city's achievements in the domain of the cultural economy.

In contrast with the classical factory towns of an earlier era, then, cities with flourishing cultural economies are places in which many aspects of work, leisure and social life ramify with one another in symbiotic interrelationship. A final concrete illustration of this point is presented by the reciprocal relationships between the music industry and the wider urban environment in Los Angeles and New York. These two cities consistently turn out streams of hit records in numbers that disproportionately and significantly exceed even those that we might expect given their great size (Scott 1999). Their success is 
built upon the localized synergies generated within the large and multifaceted clusters of musicians, production companies, recording studios, and so on, that function in core areas of both cities. Concurrently, these clusters draw at least part of their vitality from local music scenes with their vibrant mix of live entertainment venues, clubs, bars, restaurants, boutiques, and so on, and that thrive in the context of the adjacent high-density residential areas favoured by large numbers of young, single, and creative workers (cf. Watson et al. 2009).

\section{The creative city}

Landry and Bianchini (1995) can be credited with having written one of the first major statements about the creative city as a significant element of the contemporary geographical landscape. Since the publication of their work, an ever expanding flow of studies on the subject has appeared. The terms of reference of most of this work usually - and properly - go well beyond the more narrow scope of the present study with its primary focus on the cultural economy as such. That said, virtually all commentators on the topic are in accord about the importance of culture in all its forms as a key element of the creative city, if only in the sense that the cultural milieu of the city provides amenities that are highly valued by creative workers. However, unlike some of the research that has been published on creative cities (see, above all, Florida 2004), there is clearly little or no room in the analysis worked out here for claims that advanced forms of creativity in cities can be induced simply by making them attractive on the consumption side for individuals with high levels of educational attainment and "talent". Such individuals are incontestably necessary for the effective functioning of creative cities in the modern era, but they by no means represent a full set of sufficient conditions as well. To repeat an earlier point, creativity and its specific forms of expression in any given city are induced in complex socio-spatial relationships constituting the local creative field, which in turn is centrally rooted in the production, employment, and local labour market dynamics of the city. Policies that seek to promote creativity in cities must carefully adjust their priorities in light of the different ways in which these relationships intersect with one another.

A synopsis of this entire argument is presented very schematically in Figure 2, which is meant to represent a set of ideal conditions towards which some of the more advanced creative cities with dynamic cultural economies seem to be advancing at the present time, though none can be said as yet to have attained fully to this hypothetical stage of development. The central circle of Figure 2 represents the core (transactions-intensive) sectors of the local cultural economy. These sectors constitute the main locus of the city's creative energies, and indeed, without this driving structure of income, employment and growth, much of the rest must inevitably stagnate or fail. A second circle is drawn around the central circle, representing a sphere of complementary craft, fashion, and design activities (e.g. industrial design professionals, interior decorators, freelance artists, or software specialists). Important positive spillover effects can be expected to flow between the active agents in these two circles. The next element of Figure 2 represents local labour market structures and processes embodying a diversity of creative stimuli that reside especially in the ebb and flow of interpersonal contacts within the employment system. These three elements of the creative-cum-cultural economy of the city must be contextualized within a wider urban milieu, which is captured in Figure 2 in the six compartments that constitute the penultimate outer zone of the figure. These compartments represent:

(1) A local system of traditions, norms, and sites of memory (such as museums and exhibitions dedicated to local crafts or skills) through which certain kinds of creative impulses are preserved and transmitted.

(2) A visual landscape that reflects and supports the creative ambitions of the city by projecting a distinctive image and spectacle. For example, a number of older European cities seeking a creative renaissance have fashioned very effective imageries out of recycled factories and warehouses.

(3) A system of leisure opportunities and amenities that provide relevant forms of recreation, distraction and edification for the citizenry at large and for creative workers in particular.

(4) A mosaic of residential neighbourhoods offering appropriate housing and infrastructural services for workers in the urban cultural economy.

(5) A framework of education and training activities. These activities typically play a major role in supplying skilled labour for the local production system. 


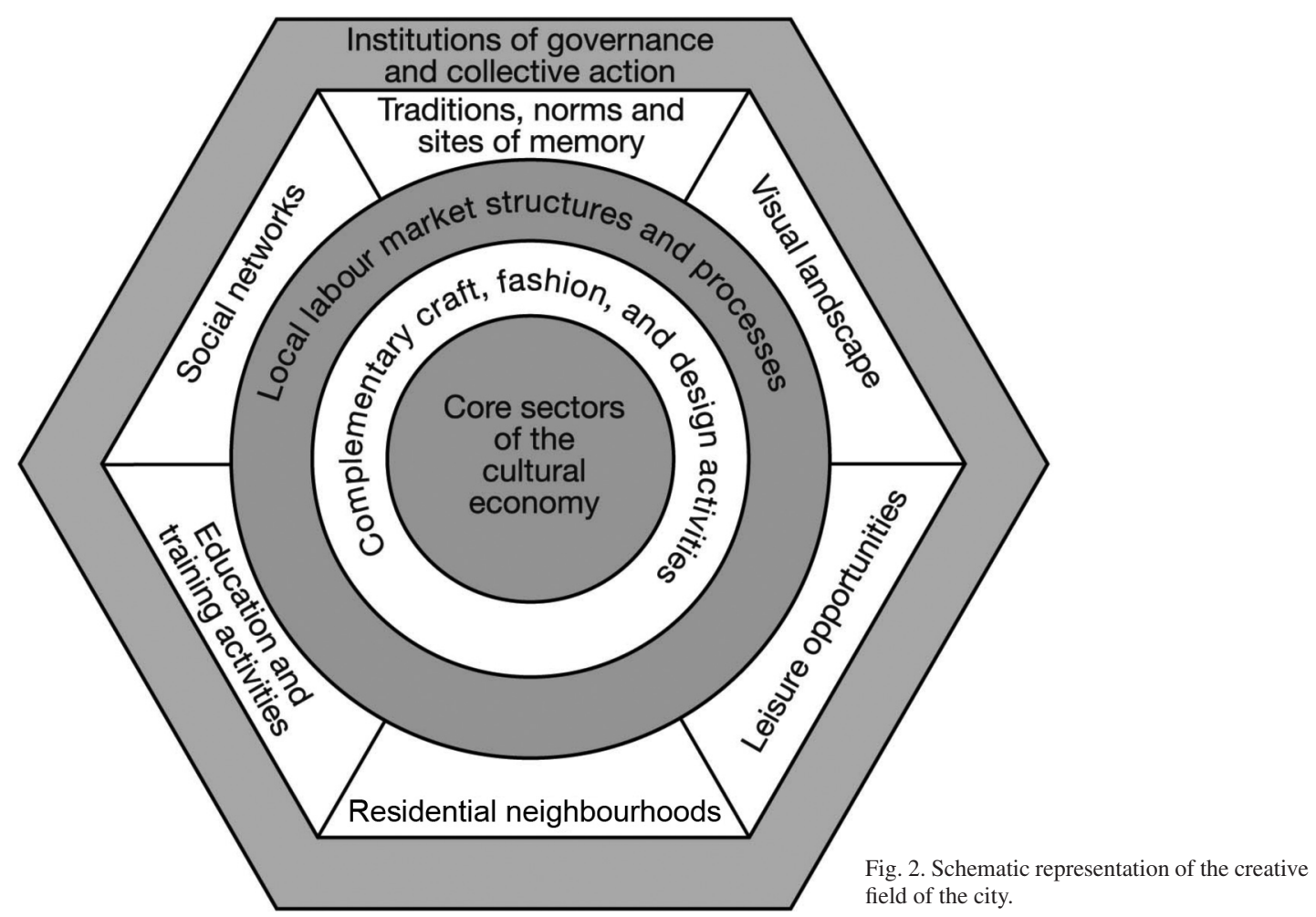

(6) A series of social networks supplementing interpersonal contacts in the workplace and by means of which creative workers maintain upto-date stocks of job-related information and know-how and other useful intelligence.

The outermost zone of Figure 2 refers to institutions of governance and collective order. These are essential for the viability of the creative city as a whole, and especially for dealing with the multiple market failures, negative spillover effects, and potentially adverse lock-in dynamics that are always present in complex socio-spatial systems. Major fashion centres, such as New York or Paris, for example, typically depend on the support of local government agencies in planning their periodic shows and buyers' weeks and in subsidizing labour training efforts. In addition, both the positive and negative externalities that so frequently reside within such systems - and especially in agglomerated production complexes - call for careful collective management.

As the cognitive-cultural economy in general moves to centre stage in contemporary capitalism, cities with these types of creative attributes are becoming increasingly evident in many different parts of the world. Indeed, it is not only cities in the narrow meaning of the term that evince this wider - and always materially grounded - creative syndrome at the present time, but also more extensive, often rural and semi-rural areas. Cooke and Lazzeretti (2007) have drawn attention to this aspect of the issue in their discussion of regional platform economies, with special reference to the case of peripheral regions endowed with unique natural, historical or cultural (e.g. culinary) assets. A dramatic illustration of this sort of platform economy is offered by the English Lake District where a spectacular natural landscape of mountains and lakes forms the backdrop to a dispersed cultural economy comprising historical and literary sites, art exhibits, festivals, revived traditional crafts, local food specialties, guided walks and cruises, wildlife reserves, and so on. Much of this argument can be boiled down to the basic proposition that in the cognitive-cultural economy of the twenty-first 
century the entire city or region is implicated in processes of learning, creativity and innovation. In the earlier era of fordism, the fountainhead of innovation resided above all in the $R \& D$ departments of large corporate entities, and the ideas produced in this context were then implemented in a top-down way on the shop floor. Top-down models of innovation have by no means disappeared, but a different and much more diffuse, bottom-up model has become increasingly important today, and this is focused above all on the innumerable small creative impulses that emanate from different segments of the local milieu and that circulate in various ways through urban space. Each of these impulses may be insignificant in its own right, but their cumulative effect over time will often be expressed in powerful and durable waves of innovation.

Finally, discussions of the creative city in recent years have often been tinged with a note of high optimism and hopefulness, especially on the part of policy makers. In view of what I have written above, there is certainly much room for a positive assessment about the possibilities of steering given cities into more creative pathways of development, though this remark must also be tempered by a clear understanding of the complexity and difficulty of the tasks involved as well as by a suitably modest set of expectations about just what policy makers can deliver in practice. Specifically, there can be no mechanical initiation of creative energy at any given place simply by bringing together different elements of Fig. 2 in the expectation that the requisite synergies will then spontaneously spring forth. To the contrary, the potential powers of the creative field are liable to remain underdeveloped unless it also unfolds reflexively with a cultural production system whose individual units of decision-making and behaviour can assertively defend their competitive interests, successfully contest wider markets, and continue to generate jobs over some extended time horizon.

One further point must be brought squarely forward in this context. In today's world, large metropolitan areas with some claim to creative dynamism are almost always characterized by a dark underbelly as represented by the bottom tier of the labour market with its disproportionate share of low-wage immigrant workers. These workers are not simply a contingent element of the cultural economy as it is currently constituted; rather, they are integral to its overall functional requirements, for they provide the basic labour inputs to the sweatshops and the low-grade services that comprise the other side of cultural economy today. There can be no truly final realization of the creative city where the stubborn social, cultural, and economic inequalities engendered by this situation remain. This is not just a question of material rewards, though more equitable economic circumstances for all must surely figure on any agenda of reform. It also raises basic issues of citizenship and democracy, and the assimilation of all social strata into the life of the city, not only for its own sake, but also as a means of giving more ample rein to the creative powers of the citizenry as a whole. In the last analysis, any credible analysis of the creative city - most emphatically if the analysis has pretensions to policy relevance - must come to terms with the intricacies of this overall model of social and economic development, and with the complex urban conditions on which it is based. That means, too, coming to terms with the rampant socio-spatial segmentation that characterizes major centres of the global cultural economy today. Most of all, it makes no sense whatever to talk of the creative city without due acknowledgement of the central concrete grid or field of relationships that instil definite content into the creative process and that sustain (or hinder) its social reproduction over time.

\section{Conclusion: the question of geographic scale}

Notwithstanding the emphasis in all of the above on specifically urban issues, the creative field that grows out of and undergirds the new economy is in practice stretched out at varying densities across the whole of geographic space. In other words, the creative field as a constellation of active ingredients necessarily has multiple scalar properties. The urban, obviously, is one especially complex level; the national is another, notably in the guise of the triple helix as identified by Leydesdorff and Etzkowitz (1997); so is the global. Other spatial and organizational levels might also be distinguished as articulations of the creative field with identifiable emergent effects (Amin and Cohendet 2004; Simmie 2004). In addition, creative impulses flow between levels and combine with one another in a diversity of ways (Bathelt et al. 2004).

All of these alternative dimensions of the creative field merit much further scrutiny, but the peculiar logic of learning, creativity and innovation that now seems to be occurring at the global level has attracted special attention from scholars in recent 
years. New communications technologies are currently bringing about major shifts in informationflow processes. Not only is it becoming possible to transmit ever larger quantities of explicit knowledge over greater distances at decreasing cost, but much tacit knowledge as well. Some theorists (e.g. Leamer and Storper 2001; Kaufmann et al. 2003) have argued that the capacities of the Internet are limited in this respect because it does not readily lend itself to ostensive interactions. This assessment is surely correct as things now stand. However, if the conjectures of Cohendet et al. (1999) and Foray and Steinmueller (2003) are on track, we can expect considerable relaxation of this limitation to occur in the future, as the Internet, in combination with embedded work stations, becomes more and more capable of handling information transfers of enormous complexity and subtlety. As this occurs, creative workers will undoubtedly tend to draw increasingly on far-flung web-based communities for sources of inspiration, a phenomenon that is already well under way, according to Sunley et al. (2008), in the British design sector. Concurrently, multinational corporations are now moving aggressively into all segments of the new cultural economy, and with the spread of their organizational webs across the globe, the creative field further extends its spatial reach.

For the present at least, the global and the local seem to encompass relatively distinctive sites of creative energy, even if they are also swiftly evolving in the direction of increasing interpenetration with one another. In any case, it is important not to conflate current processes of globalization with the imminent deliquescence of the city as a centre of learning, creativity, and innovation in its own right. Rather, globalization up this point in time has been accompanied by the emergence of an ever more differentiated global mosaic of cultural-products agglomerations, each endowed with its own idiosyncratic creative powers and assets. The thriving film and television industries of Mumbai, Beijing, Paris, London, Montreal, Tokyo, Hong Kong, Seoul, Bangkok, Mexico City and other parts of the world offer striking evidence in favour of this claim, despite the continued dominance of Hollywood in world markets. Globalization, in short, does not yet appear, as in some extreme views, to be ushering in a world of cultural uniformity. On the contrary, it is actually being played out in terms of an increasingly polycentric and polyvocal geography of cultural production. The emergence of this si- multaneously local and global creative economy raises many further questions about the ideological and political ramifications of cultural production in contemporary capitalism. That issue, however, calls for another article.

\section{Acknowledgements}

This research was supported by the National Science Foundation under grant number BCS-0749038. I am grateful to Gordon L. Clark for his critical comments on an earlier draft of this article.

\section{Notes}

1. For example, one might argue that neighbourhoods such as gentrified inner city residential areas or upgraded urban bohemias offer social contacts, services and an overall ambience that have positive direct and indirect impacts on the career trajectories of the creative workers who inhabit them. Admittedly, this is a crude conjecture as it stands, but it surely merits further exploration.

2. Pasteur's celebrated maxim to the effect that even chance discoveries require a prepared mind should be noted in this context.

3. This comment is no doubt pitched at much too general a level, though it rings true for certain kinds of aesthetic judgments, as for example in segments of the contemporary New York art market.

4. We might illustrate this overall story with any number of empirical cases. One that serves this purpose well is presented in a study by Kebir and Crevoisier (2008) of the tensions between tradition and change in the watch making industry of the Swiss Jura Region.

Allen J. Scott,

Department of Geography and

Department of Policy Studies

University of California - Los Angeles.

E-mail: ajscott@ucla.edu

\section{References}

AAGE, T. and BELUSSI, F. (2008): 'From fashion to design: creative networks in industrial districts', Industry and Innovation 15 (5): 475-491.

AMIN, A. (ed.) (1994): Post-Fordism: A Reader. Blackwell, Oxford

AMIN, A. and COHENDET, P. (2004): Architectures of Knowledge: Firms, Capabilities, and Communities. Oxford University Press, Oxford.

AMIN, A. and ROBERTS, J. (2008): 'Knowing in action: beyond communities of practice', Research Policy 37 (2): 353-369.

ASHEIM, B. T. and COENEN, L. (2005): 'Knowledge bases and regional innovation systems: comparing Nordic clusters', Research Policy 34 (8): 1173-1190.

AUTOR, D. H., KATZ, L. F. and KEARNEY, M. S. (2006): 'The polarization of the US labor market', American Economic Review 96 (2): 189-194. 
AYDALOT, P. (ed.) (1986): Milieux innovateurs en Europe. Groupe de Recherche Européen sur les Milieux Innovateurs (GREMI), Paris.

BARNES, B., BLOOR, D. and HENRY, J. (1996): Scientific Knowledge: A Sociological Analysis. Athlone, London.

BASTIDE, R. (1977): Sociologie de l'art. Payot, Paris.

BATHELT, H., MALMBERG, A. and MASKELL, P. (2004): 'Clusters and knowledge: local buzz, global pipelines and the process of knowledge creation', Progress in Human Geography 28 (1): 31-56.

BAUTÈS, N. and VALETTE, E. (2004): 'Miniature painting, cultural economy and territorial dynamics in Rajasthan, India', in SCOTT, A. J. and POWER, D. (eds): Cultural Industries and the Production of Culture. Routledge, London, pp. 207-223.

BECKER, H. S. (1982): Art Worlds. University of California Press, Berkeley, CA.

BENJAMIN, W. (1969): Illuminations: Essays and Reflections. Schocken, New York.

BOURDIEU, P. (1980): Le sens pratique. Éditions de Minuit, Paris.

BROWN, J. S. and DUGUID, P. (1991): 'Organizational learning and communities-of-practice: toward a unified view of working, learning, and innovation', Organization Science 2 (1): $40-57$.

CAMAGNI, R. P. (1995): 'The concept of innovative milieu and its relevance for public policies in European lagging regions', Papers in Regional Science 74 (4): 317-340.

COHENDET, P., KERN, F., MEHMANPAZIR, B. and MUNIER, F. (1999): 'Knowledge coordination, competence creation and integrated networks in globalised firms', Cambridge Journal of Economics 23 (2): 225-241.

COOKE, P. and LAZZERETTI, L. (2007): 'Creative cities: an introduction', in COOKE, P. and LAZZERETTI, L. (eds): Creative Cities, Cultural Clusters and Local Economic Development. Edward Elgar, Cheltenham, pp. 1-24.

COOKE, P. and MORGAN, K. (1998): The Associational Economy: Firms, Regions, and Innovation. Oxford University Press, Oxford.

CORSANI, A. (2003): 'Le capitalisme cognitif: les impasses de l'économie politique', in VERCELLONE, C. (ed.): Sommesnous sortis du capitalisme industriel? La Dispute, Paris, pp. 55-75.

CRANE, D. (1992): The Production of Culture: Media and the Urban Arts. Sage, Newbury Park, CA.

CSIKSZENTMIHALYI, M. (1990): 'The domain of creativity', in RUNCO, M. A. and ALBERT, R. S. (eds): Theories of Creativity. Sage, Newbury Park, CA, pp. 190-212.

CUCCIA, T. and SANTAGATA, W. (2002): Distretto culturale e gestione dei diritti di proprietà: la ceramica di Caltagirone. EBLA Working papers 06/2002, International Centre for Research on the Economics of Culture, Institutions, and Creativity, Università di Torino, Turin.

CURRID, E. (2007): The Warhol Economy: How Fashion Art and Music Drive New York City. Princeton University Press, Princeton, NJ.

DOSI, G. (1982): 'Technological paradigms and technological trajectories: a suggested interpretation of the determinants and directions of technical change', Research Policy 11 (3): $147-162$.

DRAKE, G. (2003): “"This place gives me space”: place and creativity in the creative industries', Geoforum 34 (4): 511-524.

FLORIDA, R. (1995): 'Toward the learning region', Futures 27 (5): $527-536$.

FLORIDA, R. (2004): Cities and the Creative Class. Routledge, London.
FORAY, D. and STEINMUELLER, W. E. (2003): 'The economics of knowledge production by inscription', Industrial and Corporate Change 12 (2): 299-319.

GIL, R. and SPILLER, P. T. (2007): 'The organizational dimensions of creativity: motion picture production', California Management Review 50 (1): 243-260.

GRABHER, G. (2001): 'Ecologies of creativity: the village, the group, and the heterarchic organisation of the British advertising industry', Environment and Planning A 33 (2): 351-374.

HALLE, D. and TISO, E. (2008): 'New York's Chelsea district: a "global" and local perspective on contemporary art', in ANHEIER, H. and ISAR, Y. R. (eds): The Cultural Economy. Sage, Los Angeles, CA, pp. 292-306.

HEMLIN, S., ALLWOOD, C. M. and MARTIN, B. R. (2008): 'Creative knowledge environments', Creativity Research Journal 20 (2): 196-210.

HENNION, A. (1981): Les professionels du disque. Une sociologie des variétés. Éditions A.-M. Métailié, Paris.

HEßLER, M. and ZIMMERMANN, C. (2008): 'Introduction: creative urban milieus - historical perspectives on culture, economy, and the city', in HEßLER, M. and ZIMMERMANN, C. (eds): Creative Urban Milieus: Historical Perspectives on Culture, Economy, and the City. Campus, Frankfurt am Main, pp. 11-38.

HUTTON, T. A. (2008): The New Economy of the Inner City: Restructuring, Regeneration and Dislocation in the TwentyFirst Century Metropolis. Routledge, London.

INDERGAARD, M. (2004): Silicon Alley: The Rise and Fall of a New Media District. Routledge, New York.

JAFFE, A. B., TRAJTENBERG, M. and HENDERSON, R. (1993): 'Geographic localization of knowledge spillovers as evidenced by patent citations', Quarterly Journal of Economics 108 (2): 577-598.

KAUFMANN, A., LEHNER, P. and TÖDTLING, F. (2003): 'Effects of the Internet on the spatial structure of innovation networks', Information, Economics and Policy 15 (3): 402 424.

KEBIR, L. and CREVOISIER, O. (2008): 'Cultural resources and regional development: the case of the cultural legacy of watchmaking', in COOKE, P. and LAZZERETTI, L. (eds): Creative Cities, Cultural Clusters and Local Economic Development. Edward Elgar, Cheltenham, pp. 48-69.

LANDRY, C. and BIANCHINI, F. (1995): The Creative City. Demos, London.

LATOUR, B. and WOOLGAR, S. (1979): Laboratory Life: The Social Construction of Scientific Facts. Sage, Beverly Hills, CA.

LEAMER, E. E. and STORPER, M. (2001): 'The economic geography of the Internet age', Journal of International Business Studies 32 (4): 641-665.

LEVY, F. and MURNANE, R. J. (2004): The New Division of Labor: How Computers are Creating the Next Job Market. Russell Sage Foundation, New York.

LEYDESDORFF, L. and ETZKOWITZ, H. (1997): 'A triple helix of university-industry-government relations', in ETZKOWITZ, H. and LEYDESDORFF, L. (eds): Universities and the Global Knowledge Economy: A Triple Helix of University-IndustryGovernment Relations. Pinter, London, pp. 155-162.

LLOYD, R (2002): 'Neo-bohemia: art and neighborhood development in Chicago', Journal of Urban Affairs 24 (5): 517-532.

MADURO, R. (1975): Artistic Creativity in a Brahmin Painter Community. Research Monograph 14, Center for South and Southeast Asian Studies, Berkeley, CA.

MAILLAT, D., and VASSEROT, J.-Y. (1986): 'Les milieux innovateurs: le cas de l'Arc Jurassien suisse', in AYDALOT, P. (ed.): Milieux innovateurs en Europe. Groupe de Recherche 
Européen sur les Milieux Innovateurs (GREMI), Paris, pp. 217-246.

MARKUSEN, A., WASSALl, G. H., DeNATALE, D. and COHEN, R. (2008): 'Defining the creative economy: industry and occupational approaches', Economic Development Quarterly 22 (1): 24-45.

MCINTYRE, P. (2008): 'Creativity and cultural production: a study of contemporary western popular music songwriting', Creativity Research Journal 20 (1): 40-52.

MENGER, P.-M. (1993) : 'L'hégémonie parisienne. Économie et politique de la gravitation artistique', Annales: Économies, Sociétés, Civilisations 48 (6): 1565-1600.

MIZZAU, L. and MONTANARI, F. (2008): 'Cultural districts and the challenge of authenticity: the case of Piedmont, Italy', Journal of Economic Geography 8 (5): 651-673.

MOLOTCH, H. (1996): 'LA as product: how art works in a regional economy', in SCOTT, A. J. and SOJA, E. W. (eds): The City: Los Angeles and Urban Theory at the End of the Twentieth Century. University of California Press, Berkeley, CA, pp. 225-275.

MONTGOMERY, S. S. and ROBINSON, M. D. (1993): 'Visual artists in New York: what's special about person and place?', Journal of Cultural Economics 17 (2): 17-39.

MORGAN, K. (1997): 'The learning region: institutions, innovation and regional renewal', Regional Studies 31 (5): 491-503.

MOULIER-BOUTANG, Y. (2007): Le capitalisme cognitif. Comprendre la nouvelle grande transformation et ses enjeux. Éditions Amsterdam, Paris

MULKAY, M. J. (1972): The Social Process of Innovation: A Study in the Sociology of Science. Macmillan, London.

NONAKA, I. (1994): 'A dynamic theory of organizational knowledge creation', Organization Science 5 (1): 14-37.

NOOTEBOOM, B. (1999): 'Innovation, learning and industrial organisation', Cambridge Journal of Economics 23 (2): 127 150.

OINAS, P. and MALECKI, E. J. (1999): 'Spatial innovation systems', in MALECKI, E. J. and OINAS, P. (eds): Making Connections: Technological Learning and Regional Economic Change. Ashgate, Aldershot, pp. 7-33.

PETERSON, R. A. and BERGER, D. G. (1975): 'Cycles in symbol production: the case of popular music', American Sociological Review 40 (2): 158-173.

POWER, D. (2002): "“Cultural industries” in Sweden: an assessment of their place in the Swedish economy', Economic Geography 78 (2): 103-127.

PRATT, A. C. (1997): 'The cultural industries production system: a case study of employment change in Britain, 1984-91', Environment and Planning A 29 (11): 1953-1974.

RANTISI, N. (2004): 'The designer in the city and the city in the designer', in POWER, D. and SCOTT, A. J. (eds): Cultural Industries and the Production of Culture. Routledge, London, pp. $91-109$.

ROOST, F. (1998): 'Recreating the city as entertainment center: the media industry's role in transforming Potsdamer Platz and Times Square', Journal of Urban Technology 5 (3): 1-21.

RUSSO, M. (1985): 'Technical change and the industrial district: the role of interfirm relations in the growth and transformation of ceramic tile production in Italy', Research Policy 14 (6): 329-343.

SANTAGATA, W. (2004): 'Creativity, fashion and market behavior', in POWER, D. and SCOTT, A. J. (eds): Cultural Industries and the Production of Culture. Routledge, London, pp. 75-90.
SCOTT, A. J. (1998): 'Multimedia and digital visual effects: an emerging local labor market', Monthly Labor Review 121 (3): $30-38$.

SCOTT, A. J. (1999): 'The US recorded music industry: on the relations between organization, location, and creativity in the cultural economy', Environment and Planning A 31 (11): 1965-1984.

SCOTT, A. J. (2000): The Cultural Economy of Cities: Essays on the Geography of Image-producing Industries. Sage, London.

SCOTT, A. J. (2004): 'Cultural-products industries and urban economic development: prospects for growth and market contestation in global context', Urban Affairs Review 39 (4): 461-490.

SCOTT, A. J. (2005): On Hollywood: The Place, the Industry. Princeton University Press, Princeton, NJ.

SCOTT, A. J. (2006): 'Entrepreneurship, innovation and industrial development: geography and the creative field revisited', Small Business Economics 26 (1): 1-24.

SCOTT, A. J. (2007): 'Capitalism and urbanization in a new key? The cognitive-cultural dimension', Social Forces 85 (4): 1465-1482.

SEITZ, J. A. (2003): 'The political economy of creativity', Creativity Research Journal 15 (4): 385-392.

SIMMIE, J. (2004): 'Innovation and clustering in the globalised international economy', Urban Studies 41 (5-6): 1095-1112.

STERNBERG, R. J. and LUBART, T. I. (1999): 'The concept of creativity: prospects and paradigms', in STERNBERG, R. J. (ed.): Handbook of Creativity. Cambridge: Cambridge University Press, Cambridge, pp. 3-15.

STORPER, M. (1996): 'Institutions of the knowledge-based economy', in FORAY, D. and LUNDVALL, B.-Å. (eds): Employment and Growth in the Knowledge-Based Economy. Organisation for Economic Co-operation and Development, Paris, pp. 255-286.

STORPER, M. and SCOTT, A. J. (2009): 'Rethinking human capital, creativity and urban growth', Journal of Economic Geography 9 (2): 147-167.

SUNLEY, P., PINCH, S., REIMER, S. and MACMILLEN, J. (2008): 'Innovation in a creative production system: the case of design', Journal of Economic Geography 8 (5): 675-698.

TÖRNQVIST, G. (2004): 'Creativity in time and space', Geografiska Annaler: Series B, Human Geography 86 (4): $227-$ 243.

URSELL, G. (2000): 'Television production: issues of exploitation, commodification and subjectivity in UK television labour market', Media, Culture and Society 22 (6): 805-825.

UZZI, B. and SPIRO, J. (2005): 'Collaboration and creativity: the small world problem', American Journal of Sociology 111 (2): 447-504.

voN HIPPEL, E. (1988): The Source of Innovation. Oxford University Press, Oxford.

WATSON, A., HOYLER, M. and MAGER, C. (2009): 'Spaces and networks of musical creativity in the city', Geography Compass 3 (2): 856-878.

WENTING, R. (2008): The Evolution of a Creative Industry: The Industrial Dynamics and Spatial Evolution of the Global Fashion Design Industry. Geomedia, Utrecht.

WHITE, H. C. and WHITE, C. A. (1965): Canvases and Careers: Institutional Change in the French Painting World. Wiley, New York.

ZUKIN, S. (1991): Landscapes of Power: From Detroit to Disney World. University of California Press, Berkeley, CA. 